\title{
Simplification of Chrome-Cobalt Partial-Denture Casting Procedure
}

\author{
E. R. DOOTZ, R. G. CRAIG, and F. A. PEYTON \\ School of Dentistry, University of Michigan, Ann Arbor, Michigan
}

The customary practice for casting a partial-denture framework by imbedding the waxed-up refractory cast in an outer core of investment involves considerable investment material (approximately $400 \mathrm{gm}$.) per casting. Also, the time interval for producing a casting (investing and burnout) is long. Usually 1 hour is provided for the investment to harden after investing the pattern, and 3-4 hours are allowed for the burnout period, depending on size and type of material (wax or plastic) that has been used to prepare the pattern. The total time necessary, therefore, for producing a casting, from the time of investing to the time of casting, is between four and five hours.

A technique has been developed using a modified sodium silicate shell-casting process which allows for the casting of a partial-denture framework within 1 hour, from the time of investing to casting, when

This investigation was supported by Research Grant DA-49-007-MD938 between the Office of the Surgeon General, Department of Army, and the University of Michigan.

Received for publication August 14, 1964. using high melting chrome-cobalt alloys, and 2 hours when using low melting alloys. This time includes the investing (dipping and dusting of shell) of approximately $2 \frac{1}{2}$ minutes for an average casting and a burnout period of 30 minutes for high heat techniques and $1 \frac{1}{2}$ hours for low heat techniques.

The surfaces of the casting appear to be as smooth as those obtained by present techniques. A preliminary study of the accuracy of five castings in each of the following groups indicates that they are $-0.31 \pm 0.14$ per cent for high melting alloys and $+0.39 \pm 0.16$ per cent for low melting alloys. (Other methods produce castings that vary in size from -0.8 to +0.7 per cent.) Conventional sprueing and casting methods are used. Significantly less refractory material is used ( $30 \mathrm{gm}$.) when compared to conventional techniques (400 gm.). In addition to producing castings with small amounts of investment material, and shortening the in-lab-time per casting, there is the advantage of a shorter burnout period, with a saving in cost of operating the burnout furnaces.

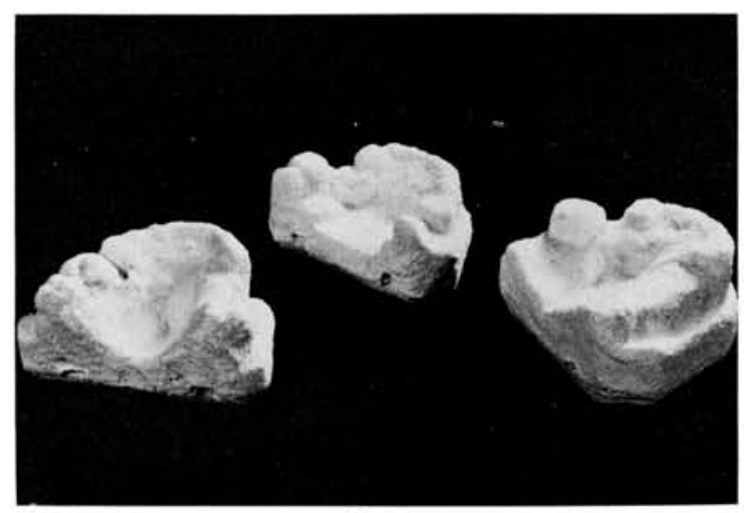

Fig. 1

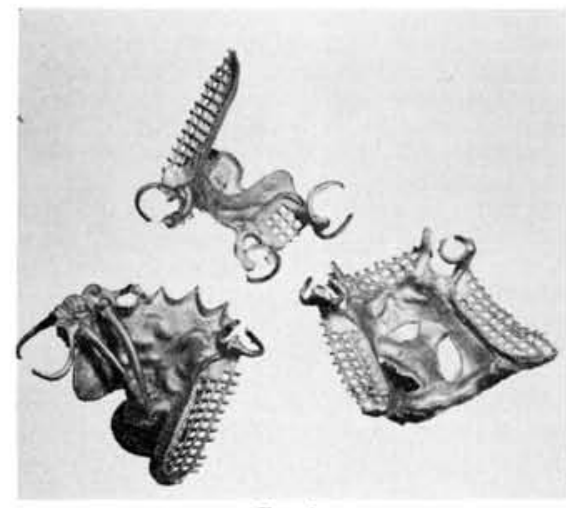

FIG. 2

FIG. 1.- Shell layer applied to wax pattern on refractory model. Pattern sprued through base of model

Frg. 2.- Sandblasted castings as recovered from shell investment 